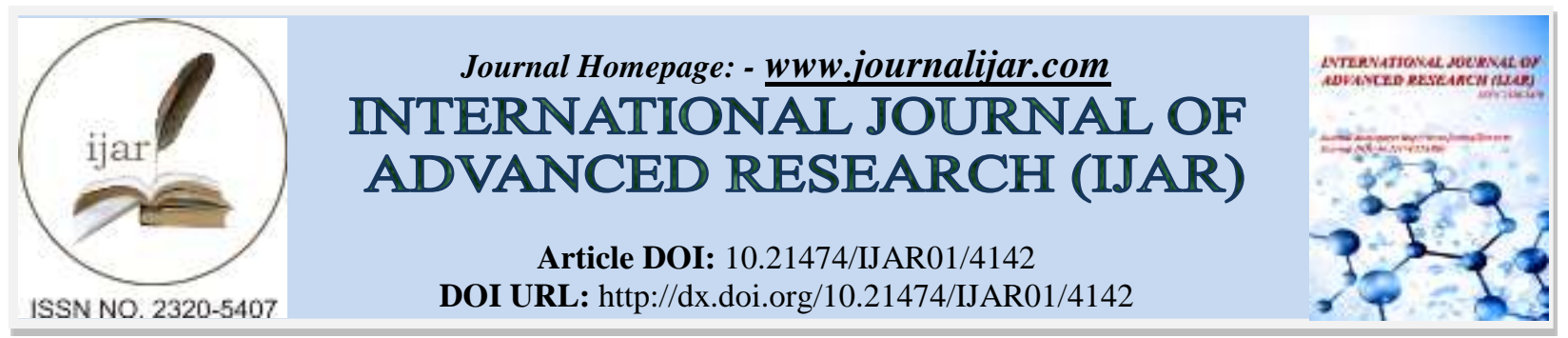

RESEARCH ARTICLE

\title{
MERMAID BABY SYNDROME WITH GENU RECURVATUM.
}

Dr Avneet Singh Sandhu ${ }^{1}$,Dr Gyan Ranjan ${ }^{2}$, Dr Shashank Singh ${ }^{2}$ and Dr Santosh Kumar ${ }^{3}$.

1. MBBS, MD(Pediatrics) student, MGM Medical college \& LSK hospital, Kishanganj,Bihar.

2. MBBS,MS(Orthopaedics) student, MGM medical college \& LSK hospital, Kishanganj, Biha.

3. MBBS,MD ;Asst Professor (dept of pediatrics).

\section{Manuscript Info}

Manuscript History

Received: 09 March 2017

Final Accepted: 02 April 2017

Published: May 2017

\section{Abstract}

Copy Right, IJAR, 2016,. All rights reserved.

A 32 year old female with gravida 3 came to emergency department with lower abdominal pain in $36^{\text {th }}$ week of pregnancy. She had not received regular antenatal care. Her previous pregnancies were uneventful and delivered babies are active and healthy at present. There was no significant family and treatment history. Ultrasonography of abdomen showed live fetus with oligohydramnios and bilateral renal agenesis and fused lower extremities. She underwent vaginal delivery a live malformed male baby. The baby had cleft palate, malformed ears, imperforate anus, fused lower lims with genu recurvatum and syndactyly, rudimentary phallus with no urethral opening (figure 1).Prognosis was explained to the parents.The baby collapsed on day 2 of life.

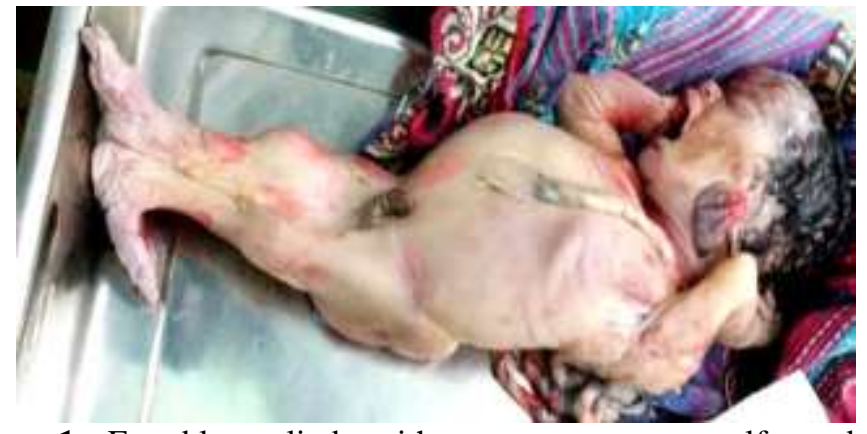

Figure 1:- Fused lower limbs with genu recurvatum, malformed ear.

Sirenomelia or Mermaid baby syndrome is an extreme example of the caudal regression syndrome ${ }^{1}$. Embryologically persistence of vitelline artery led to caudal blastemal defect resulting in sirenomelia ${ }^{2}$. In this syndrome the lower limbs are fused and bears resemblance to mermaid's tail of Greek mythology. It is classified into sympus apus with no feet, sympus unipus if one foot is seen, and sympus dipus if two feet are present, as in our case $^{3}$. Severe malformations of the gastrointestinal, genitourinary, cardiovascular and musculoskeletal systems are usually present. Oligohydromnios secondary to severe renal dysplasia is universal ${ }^{3}$. Maternal diabetes is implicated to associated with upto $22 \%$ fetuses of caudal regression ${ }^{4}$.Other important risk factors are tobacco use, retinoic acid and heavy metal exposure to the mother ${ }^{5}$. It carries a very poor prognosis. Antenatal ultrasonography can help 
in early detection of this syndrome and termination of pregnancy can be planned thereafter. Initial treatment of these newborns includes supportive care and diverting colostomy. However multidisciplinary surgical approach involving various specialties is required to increase the survival ${ }^{6}$.

\section{References:-}

1. Duhamel B. From the Mermaid to Anal Imperforation: The Syndrome of Caudal Regression. Arch Dis Child 1961; 36: 152-5.

2. Saxena R, Puri A. Sirenomelia or mermaid syndrome. The Indian Journal of Medical Research. 2015;141(4):495. doi:10.4103/0971-5916.159323.

3. Reddy KR, Srinivas S, Kumar S, Reddy S, Prasad H, Irfan GM. Sirenomelia: A Rare Presentation. Journal of Neonatal Surgery. 2012;1(1):7.

4. González-Quintero VH, Tolaymat L, Martin D, Romaguera RL, Rodríguez MM, Izquierdo LA. Sonographic diagnosis of caudal regression in the first trimester of pregnancy. J Ultrasound Med. 2002;21:1175-8.

5. Naveena S, Mrudula C. Sirenomelia - The mermaid syndrome: A case report. IOSR J Dent Med Sci. 2013;7:01-4.

6. Messineo A, Innocenti M, Gelli R, Pancani S, Lo Piccolo R, Martin A. Multidisciplinary surgical approach to a surviving infant with sirenomelia. Pediatrics 2006; 118: e220-3. 